\title{
La mirada de Jesús sobre el poder
}

\author{
Rafael Aguirre \\ UNIVERSIDAD DE DEUSTO. BILBAO. ESPAÑA \\ rafael.aguirre@deusto.es
}

El presente trabajo es de naturaleza exegética, pero tiene una preocupación explícitamente teológica ${ }^{1}$. Este pequeño ensayo de exégesis teológica no pierde de vista tres claves: a/ Unos textos, fundamentalmente los evangelios, considerados inspirados y canónicos, que nos remiten al testimonio de Jesús de Nazaret, el gran punto de referencia de la vida cristiana. b/ La exégesis no puede ser no crítica y, por tanto, tiene que tener en cuenta el contexto, los condicionamientos y las funciones sociales de los textos. c/Abordar la relación de Jesús con el poder requiere una exégesis, que tiene muy presente el contexto del siglo I, pero que no puede despreocuparse de cuestiones que están muy vivas en la sociedad y en la Iglesia de nuestros días

\section{PODER, AUTORIDAD y CONTEXTO SOCIO-HISTÓRICO}

Comienzo con una serie de consideraciones de diferente naturaleza que nos servirán para contextualizar el análisis posterior de unos textos evangélicos, que considero el núcleo de este trabajo.

\section{A. Poder y autoridad}

Los seres humanos vivimos normalmente en medio de complejas relaciones de poder. Max Weber ${ }^{2}$ distinguió cuidadosamente entre poder y autoridad. Por poder se entiende la capacidad para imponer comportamientos a otros, a veces venciendo grandes resistencias. Se diferencia

\footnotetext{
1 Su origen es una ponencia presentada en las Jornadas de la Sociedad Chilena de Teología, en octubre de 2013. Agradezco mucho las observaciones que se hicieron en la discusión posterior y que me han servido para matizar el texto.

2 Economia y sociedad (FCE, México 1984).
} 
de la autoridad entendida como la posibilidad de conseguir obediencia por cierta capacidad intrínseca de la persona o del contenido de lo que propone. El poder es una realidad histórica ineludible, que no se puede demonizar, pero con una importante proclividad impositiva y coercitiva y, por tanto, hay que saberlo administrar y controlar para que su uso sea socialmente positivo. El poder puede estar respaldado por una autoridad, cuya naturaleza puede ser muy diferente, o, simplemente, puede apoyarse en la mera fuerza. La autoridad puede estar desprovista de poder reglado socialmente y, sin embargo, ejercer un influjo social, incluso decisivo. En este caso hablaríamos de autoridad moral, que normalmente requiere coherencia personal y ejemplaridad ${ }^{3}$. Pero los lindes entre poder y autoridad, a veces, se entrecruzan y, por eso, puede decirse que la autoridad moral goza de un cierto poder, porque suscita responsabilidad siempre respetando la libertad, porque saca a la luz los mecanismos de dominación, porque tiene influencia social. Es propio de la pura autoridad moral no tener poder coercitivo alguno.

\section{B. La situación socio-histórica del ministerio de Jesús}

Jesús no fue un profeta intemporal y, por tanto, tenemos que tener muy presentes la situación social en la que vivió. El marco general era el Impero Romano, que en los evangelios se deja ver relativamente poco, pero que es un contexto englobante, que todo lo condiciona y que debe tenerse muy en cuenta. El Imperio proporcionaba una tranquilidad externa, pero estaba asentado, en última instancia, en un implacable poder militar. Pero el Imperio no era solo una superestructura política (su burocracia era más bien limitada), sino que suponía todo un entramado social de poderes. Destaquemos $\operatorname{dos}^{4}$. Primero, la familia, de carácter patriarcal (jerárquica, piramidal), que era la estructura básica de aquella sociedad y el modelo de todo el orden social. Esto está muy presente en la vida de Jesús y en todo el NT. El segundo entramado consistía en las relaciones de patronazgo, de patrón-cliente, que en cascada organizaban toda la vida social. Un patrón tenía una serie de clientes a los que proporcionaba medios de subsistencia, ayudas, favores. Los clientes, a su vez, proporcionaban honor al patrón. Un patrón era más honorable

3 Javier Gomá, Ejemplaridad pública (Taurus, Madrid 2010).

4 La bibliografía es inmensa. Puede verse K. C. Hanson - D. E. OAkman, Palestine in the time of Jesus. Social structures and social conflicts (Fortress, Minneapolis 1998) con amplia bibliografía. 
cuantos más clientes tenía. Por su parte, los clientes pugnaban por serlo de un patrón muy honorable. El emperador era el patrón supremo. Los herodianos -acercándonos ya a nuestro tema- eran clientes del emperador, dependían de su apoyo y benevolencia, pero tenían, a su vez, sus propios clientes (el grupo "herodiano", cierta aristocracia galilea...).

Dentro del Imperio Romano los judíos tenían una situación muy peculiar. El Templo de Jerusalén era la institución central, y la clase dirigente se ramificaba en letrados, aristocracia sacerdotal y aristocracia laical. Era una estructura teocrática y el poder se legitimaba con el etnomito del pueblo elegido, que había que asegurar a toda costa (leyes de pureza).

\section{Dos rasgos decisivos de Jesús}

Desde el punto de vista histórico dos elementos son claves y están relacionados con el poder: que Jesús anuncia el Reinado de Dios y que fue crucificado.

El Reinado de Dios suponía la confrontación con los imperios que habían oprimido con su poder al pueblo judío. Hay una referencia a los capítulos 2 y 7 del libro de Daniel. En el capítulo 7 se describe una visión de cuatro bestias feroces, espantosas, que surgen del mar y que representan a los poderes sucesivos que han ido oprimiendo al pueblo judío. Después, el contraste: un ser humano, no una bestia feroz, el Hijo del hombre $(7,13-15)$, que no surge del abismo de las aguas, sino que va sobre las nubes del cielo y se encamina hacia el trono donde está "el anciano de muchos días”, el trono de Dios, el cual le entregó el poder, el honor y el reino. Representa al pueblo de los justos que, contra todas las apariencias, va a prevalecer frente a los poderes terribles que le han oprimido $(7,15-27)$.

Jesús anuncia el Reinado de Dios al pueblo de Israel, que se debate en una situación crítica, y es un mensaje de resistencia y esperanza. El proyecto de Jesús no es fundar una institución propia, sino la renovación de Israel para que acoja el Reinado de Dios. Una particularidad importante: Jesús, que tanto habla del Reinado de Dios, nunca llama a Dios rey, sino padre/Abbá . Acoger el Reinado de Dios implica fraternidad, superar las relaciones de poder; cambiar la sociedad es el proyecto de Jesús.

Aquí hay que recordar los trabajos de J. Jeremías muy conocidos y que no hace falta citar. Sus conclusiones en lo fundamental encuentran una aceptación muy 
Se podría concretar más, pero apenas es posible hacerlo en este lugar. Galilea en tiempo de Jesús estaba en pleno proceso de transformación, de integración en el Imperio por obra de la dinastía herodiana. Se estaba dando el paso de una economía de reciprocidad (prácticamente de subsistencia familiar, con trueque con los cercanos) a una economía de redistribución, en la que un poder central fuerte acumulaba los recursos (se estaba imponiendo grandes cargas fiscales), que luego se distribuían de forma muy desigual. Todo esto estaba provocando la ruptura de las formas tradicionales de vida del campesinado galileo, que se encontraba en una situación insostenible. En esta coyuntura, ligera y brevemente evocada, hay que situar a Jesús, cuyo mensaje es sumamente crítico con la élite, pero que encontraba un eco muy positivo entre los sectores campesinos en general y entre los socialmente estigmatizados (enfermos, pecadores...) en particular.

El otro dato histórico no necesita explicación. La cruz de Jesús es la reacción del poder (el romano y el judío subordinado), que se vio amenazado. No discuto ahora dónde radicaba la amenaza, pero el dato es de suma importancia para nuestro tema.

\section{La autoridad de Jesús}

Hay un tercer dato con una indudable base histórica. Jesús posee una insólita autoridad, que el pueblo percibe con asombro, que atrae, y que las autoridades consideran un peligro e intentan desacreditarle ("actúa por el poder de Beelzebú": Mt 12, 24). "Les enseñaba como quien tiene autoridad y no como los escribas” (Mc 1, 22). “¿Qué es esto? ¡Una doctrina nueva, expuesta con autoridad! Manda hasta a los espíritus impuros y le obedecen" (Mc 1, 27). "El Hijo del hombre tiene poder de perdonar los pecados" $(2,10)$. En el gesto del Templo esta autoridad se pone de manifiesto de manera insoportable para las autoridades sacerdotales que le piden cuentas: “¡con qué poder haces estas cosas?” (Mc 11, 28. 29. 33).

No es una autoridad legal, porque Jesús no puede presentar nada que acredite sus conocimientos ni tiene estudios de escriba. Tampoco goza de una autoridad tradicional, la que podría conferirle el ser paterfamilias de una casa prestigiosa o pertenecer a un linaje al que se atribuye

amplia. En el Evangelio de Mateo hay textos en que sí se llama a Dios rey, pero son claramente redaccionales. 
autoridad hereditaria (como era el caso con las familias sacerdotales). Podríamos decir que es una autoridad carismática, que hunde sus raíces en una experiencia profunda personal y encuentra eco en la gente, que percibe la autenticidad y ejemplaridad de esta vida.

Los evangelios usan la palabra griega exousia. Ousia designa lo que se es o se tiene. Ex indica procedencia, "de". La exousia es la autoridad que sale de dentro ${ }^{6}$.

En sus palabras y acciones Jesús transparente una profunda experiencia de Dios y esto le confiere una gran libertad y explica su autoridad. El mismo expresa su unión con Dios: "todo me ha sido entregado por mi Padre" (Mt 11, 27) 7 . Creo que históricamente no se puede explicar a Jesús, su vida y su forma de actuar, sin recurrir a su experiencia religiosa.

6 El término exousia expresa autoridad, que se manifiesta en la enseñanza (Mc 1, 22. 27), en el perdón de los pecados (Mc 2, 10), en la actitud respecto al Templo (Mc 11, 28. 29. 33). Puede referirse al poder/autoridad de Satanás sobre el mundo (Lc 4, 6) y al poder/autoridad de Dios (Mt 28, 18, 9, 8); también a la autoridad humana (Mt 8, 9; Lc 7, 8; 23, 7; 20, 2 0; Mc 13, 4). El término dynamis se emplea preferentemente para designar los milagros (Mc 6, 2. 5. 14; 9, 39; Mt 7, 22; 11, 20, 21. 33), el poder de Dios y su manifestación gloriosa (Mc 9, 1; 12, 24; 13, 26; Lc 1, 36; 4, 14; 24, 49). Puede ser paráfrasis para designar a Dios (Mc, 14, 62). Puede ser la fuerza divina que viene sobre los humanos, que mueve a Jesús y actúa como una potencia interna sobrehumana (Lc 1, 35; 4, 14; 8, 46 y Mc 5, 30). En ocasiones dynamis se usa en paralelo con exousia (Lc 9, 1; 4, 36; 1, 17). Hay un cierto solapamiento entre dynamis y exousia, pero existe una diferencia: dynamis es poder, potencia, que viene más explícitamente de Dios y actúa de forma más maravillosa. También se usa para evocar a Dios o su manifestación. Exousia designa preferentemente la autoridad que se desarrolla en el marco de las relaciones humanas. En última instancia la autoridad de Jesús proviene de que es el enviado de Dios $(2,18)$ y puede comunicársela a los discípulos (Mc 3, 15; 6, 7). Dynamis aparece unas 400 veces en los LXX. Exousia solo en los libros griegos. Sin embargo existe la palabra hebrea râsût, que significa autoridad, pero que no aparece en el NT, y también la palabra aramea rêsûtâ, que significa autoridad, facultad, derecho y libertad para hacer algo. Cfr. Artículos en KitTel, Theological Dictionary of the New Testament (Eerdmans, Grand Rapids 1933 y ss), "exousia" (W. Foester, II 560-575) y "dynamis" (W. Grundmann, II 284317). O. Betz, "Poder", en Lothar Coenen - Eric Beyreuther - Hans Bietenhard, Diccionario Teológico del Nuevo Testamento, Vol. III, (Sígueme, Salamanca 1980), 385-395. Artículos en Horst Balz - Gerhard Schneider, Diccionario exegético del Nuevo Testamento (Sígueme, Salamanca 1996): “dynamis" (G. Friedich, I, 1080 188) y "exousia" (I. Broer, I, 1446-1453).

7 Este punto, que como estoy diciendo se encuentra ya en el Jesús histórico, experimenta un gran desarrollo teológico en el Evangelio de Juan: "el Padre y yo somos uno" $(10,30)$, y muchos otros textos. 
Un defecto notable de la numerosa investigación histórica actual sobre Jesús es que, salvo raras excepciones, no dan la importancia debida a su experiencia religiosa. Pronto sus discípulos dieron una explicación teológica de esta autoridad de Jesús: fue especialmente ungido por el Espíritu, le ha sido concedida por el Padre ("Me ha sido dado toda autoridad/ exousia en el cielo y en la tierra...”).

Llegamos a algo muy importante: la de Jesús es una autoridad sin poder coercitivo. Es lo que antes he llamado autoridad moral. Es la autoridad de la verdad, de la autenticidad, de la ejemplaridad. Pero respeta absolutamente la libertad. Más aún, rechaza el poder coercitivo, que usa la fuerza, como una tentación, como algo que le desvía de su camino. El poder fue la gran tentación de Jesús. Le tientan para que recurra al poder, con toda su dimensión histórica y coercitiva, la gente que le quiere hacer rey, el diablo, sus discípulos, los que se burlan a los pies de la cruz.

Por su importancia adelanto algo que, quizá lógicamente, debería decirse más tarde: precisamente porque Jesús prepara para la plenitud humana definitiva provocada por la irrupción escatológica de Dios, rechaza el uso del poder, que por necesario que sea históricamente, es siempre manifestación de lo provisional y relativo.

\section{LAS ANSIAS DE PODER DE LOS DISCíPULOS}

Estas consideraciones históricas y contextuales nos capacitan como lectores competentes de unos textos a los que nos acercamos como testimonios creyentes.

El Evangelio de Marcos se dirige a unas comunidades, en torno al año 70, en las que inevitablemente se plantea cómo organizarse. Tiene que abordar, por tanto de una forma nueva el problema del poder, del liderazgo, de la vida comunitaria de unos grupos. Y esto se refleja en el relato teológico que hace de la vida de Jesús. Vamos a considerar la sección central, el camino a Jerusalén $(8,27-10,45)$, que está jalonada por los tres anuncios de la pasión, la respuesta en todos los casos de incomprensión de los discípulos, a la que sigue una enseñanza de Jesús sobre el poder y el servicio.

La mal llamada "confesión de Pedro" es la escena central del evangelio, a partir de la cual el relato experimenta un giro radical $(8,27-35)$. La gente tiene un concepto positivo de Jesús ("unos dicen que es Elías, 
otro que uno de los profetas...”). "Pero vosotros “¿quién decís vosotros que soy yo?", pregunta a los discípulos. Como siempre Pedro es el portavoz: "tu eres el Mesías". El lector sabe que la respuesta es teóricamente correcta. El evangelio de Mc comienza así: "Inicio del evangelio de Jesús, Mesías e Hijo de Dios” $(1,1)$. Por eso es chocante que Jesús mantenga, al menos, una reserva ante la respuesta de Pedro: impone enérgicamente silencio (v. 30). No le interesa la ortodoxia de la formulación, sino la práctica que desarrolla. En efecto, entonces "empezó a enseñarles que el Hijo del hombre debía sufrir mucho..." $(8,31)$. Es el primer anuncio de la pasión. "Hablaba de esto abiertamente" (v. 32).

Hay un contraste:

Mesianismo de Jesús: impone silencio enérgicamente

Camino de la cruz: hablaba de esto abiertamente

Hay otro contraste: quien acaba de confesarle como Mesías, le reprende porque no acepta el camino de la cruz: "Pedro, tomándolo aparte, se puso a reprenderle". Pero Jesús "mirando a los discípulos" (Pedro expresaba el sentir de todos) reprendió a Pedro". Pedro reprende a Jesús y Jesús reprende a Pedro. Se utiliza un verbo griego, epitimâ̂, que es muy fuerte.

A continuación vienen unas palabras de Jesús, que muy frecuentemente se traducen de forma incorrecta. No voy ahora a justificarlo filológicamente, pero dicen así: "ponte detrás de mí, Satanás, porque tus pensamientos no son los de Dios, sino los de los hombres" (v. 33) ${ }^{8}$. Pedro es Satanás en la medida en que espera que Jesús siga el camino del mesianismo judío convencional, glorioso, vencedor de los enemigos del pueblo, que establece su propio reinado, y no acepta el camino que Jesús empieza a proponer, el del servicio que acaba en la cruz. Pero Jesús no le pide a Pedro simplemente que se vaya y se aleje (se suele traducir comúnmente "apártate de mí...). Le dice "ponte detrás de mí" (hupage opisô mou); la misma expresión que utiliza en el versículo siguiente: "si alguien quiere venir detrás de mí...”; es la misma expresión griega en dos versículos seguidos que, por tanto, hay que traducir igual en ambos casos. Es decir Jesús está reproponiendo a Pedro y a los discípulos de la primera hora, el seguimiento y que se pongan detrás de él ahora que el camino se ve que pasa por la cruz.

\footnotetext{
Santiago Guijarro, “'Vete detrás de mí, Satanás'. Exégesis y traducción de Mc 8,
} 33 c (par. Mt 16, 23b)”, Salmaticensis 58 (2011) 7-18. 
Toda esta sección está atravesada por una serie de tensiones:

entre los pensamientos de Dios y los de los hombres entre el camino del éxito y el camino de la cruz entre el Mesías del poder y la fuerza y el Mesías del servicio y la libertad entre el Dios todopoderoso y el Dios misericordioso entre la Iglesia del prestigio y del poder y la Iglesia del servicio y de los pobres (y de la autoridad moral).

Después de estas palabras a los discípulos, Jesús enseña a ellos y a la gente. Penetra en el valor humanizante y alternativo de su opción: "quien quiera ganar su vida, la perderá, pero quien la entregue por la causa del evangelio (del Reino) la ganará". Es un punto clave de la enseñanza de Jesús, la invitación a entrar en la lógica del don" ${ }^{9}$, del descentramiento del yo, de la entrega gratuita, de superar la mera reciprocidad. Es la lógica abierta por el Reinado de Dios, que ensancha el horizonte de la vida humana, enriquece las posibilidades de actuación y aumenta la creatividad moral. La lógica del don implica la imitación de un Dios, conocido a través de Jesús, que es entrega de vida, misericordia, perdón, amor infinito. Cuando en la historia humana se enciende una chispa de desinterés y gratuidad vislumbramos el misterio del Dios de Jesús. Esta perspectiva se desarrolla especialmente en el Sermón del Monte.

Jesús propone aceptar el Reinado de Dios para transformar la historia, en buena medida para revertirla (como gustaba decir a Ignacio Ellacuría), para disminuir y sustituir -siempre de forma limitada dada nuestra condición humana- la dinámica del poder por la dinámica del servicio.

\section{Disputas Por El PODER EN LA IGLeSia}

Un poco más adelante Jesús anuncia por segunda vez su pasión y muerte $(9,31)$. Como siempre sigue la incomprensión total de los discípulos. "Ellos no entendían lo que les decía y temían preguntarle" (v. 32), quizá porque vislumbraban las peligrosas consecuencias que aquello acarreaba para el grupo.

Una vez "en casa" (v. 33), lugar de reunión de la comunidad, Jesús entabla un diálogo con los Doce. La paradoja es brutal: por el camino,

\footnotetext{
Maurice Godelier, El enigma del don (Paidós, Barcelona 1998); Francesc Torralba, La lógica del don (Khaf, Madrid 2012) con amplia bibliografía.
} 
mientras seguían a Jesús, iban discutiendo a ver "quién era el mayor entre ellos". Estamos asistiendo a un conflicto que se daba en la comunidad de Mc; podríamos añadir: como tantas veces sucede en la iglesia. Los Doce han interiorizado totalmente los valores hegemónicos sobre el poder, el prestigio y el honor. Y Jesús vuelve a la carga: "si alguien quiere ser el primero que se haga el último de todos y el servidor de todos" (9, 35: Mc subraya de todos). Después pone un niño en medio y lo abraza. Téngase en cuenta que en la mentalidad judía de la época no existía ninguna idealización moral o religiosa del niño: el niño era el no-valor, el incapaz de cumplir la ley. En la Misná se lee: "sueño mañanero, vino al mediodía y palabrería con los niños, sacan al hombre del mundo" (Abot III, 10). Estas cosas - perder el tiempo con los niños entre ellas- distraen a los adultos de lo importante, como el estudio de la Torá y de las obras buenas. El gesto de Jesús y las palabras que lo acompañaban tenían que resultar chocantes y sorprendentes. El lugar central ya no corresponde ni a Pedro ni a Juan ni a Santiago, sino a un niño cualquiera, a un necesitado que ni siquiera pertenece al grupo. La comunidad de Jesús tiene que ser servidora y acogedora de quienes son como aquellos niños, de los desvalidos y de los que no cuentan.

El amor de Jesús a los niños pone claramente de manifiesto la postura que debe adoptarse en la comunidad frente a los pequeños y a los poco $\operatorname{considerados}^{10}$. "Quien a uno de estos más pequeños recibe a mí me recibe". Estas palabras nos llevan directamente a las decisivas de Mateo 25: quien acoge y ayuda a los hambrientos y sedientos, a los forasteros y desnudos, a los encarcelados o enfermos, lo hacen con el mismo Hijo del hombre.

Cuando en un grupo humano surgen las disputas por el poder y por los primeros puestos, inevitablemente nacen las divisiones y se rompe la fraternidad. Además el deseo de poder genera actitudes sectarias, que se caracterizan por el celo por monopolizar los bienes y deslindar las fronteras con otros. Es lo que vemos en el episodio que sigue. Juan le dijo: "Maestro hemos visto a uno que expulsaba demonios en tu nombre y no viene con nosotros y tratamos de impedírselo porque no venía con nosotros". Pero Jesús dijo: "No se lo impidáis... pues el que no está contra nosotros está por nosotros" (Mc 9, 38-40).

10 J. Gnilka, El Evangelio según San Marcos. Mc 8, 27-16, 20. Vol. II (Sígueme, Salamanca 1986) 65. 
Antes Pedro se oponía a la debilidad de Jesús; ahora Juan rechaza lo que podríamos llamar la "debilidad eclesial". Se ufana de haber impedido expulsar demonios en nombre de Jesús a uno "que no viene con nosotros". Pero Jesús, que sustituye el ansia de poder por la entrega a los necesitados y por el servicio, critica este concepto cerrado de comunidad, que pretende monopolizar el espíritu de Jesús, y promueve una comunidad abierta, consciente de que el Reino de Dios la desborda y se goza con ello.

\section{SerVicio y no POder (MARCos 10, 32-45)}

El relato evangélico no solo insiste, sino que profundiza en el poder como tentación y en el servicio como actitud. El tercer anuncio de la pasión es especialmente explícito (Mc 10, 32-34).

La incomprensión de los discípulos es también especialmente fuerte. Los hijos del Zebedeo, de los primeros que le han seguido y de los más vinculados a Jesús, le piden: "Concédenos que nos sentemos en tu gloria, uno a tu derecha y otro a la izquierda" $(10,37)$. Buscan los puestos de honor. Están pensando en el reino mesiánico, pero para Mc hay una clara referencia a la comunidad de los seguidores de Jesús. En todo caso se está presuponiendo una visión piramidal de las relaciones humanas y en el ejercicio habitual del poder. "No sabéis lo que pedís", les dice Jesús. Sigue un diálogo, con una notable carga irónica creo yo, sobre si pueden beber del cáliz y recibir el bautismo, que esperan a Jesús. Los Zebedeos se consideran plenamente capaces de participar en el destino de Jesús.

Pero los otros diez se indignan contra Santiago y Juan. Todos aspiran a los primeros puestos, y así -como hemos visto- surgen las rencillas y se rompe la fraternidad. Entonces Jesús interviene con unas palabras especialmente rotundas que culminan toda la sección ${ }^{11}$. Conviene que las leamos atentamente:

Comienza diciendo "los que parecen ser jefes (es la traducción exacta: oi dokountes arjein) de las naciones las dominan como señores absolutos y los grandes las oprimen con su poder...". La expresión "parecen ser jefes” está cargada de ironía y profundidad. Parecen ser jefes, tener el poder, pero, en realidad están atrapados y son piezas de un sistema de

11 Alberto de Mingo kaminouchi, 'But It Is Not So Among You'. Echoes of Power in Mark 10, 32-45 (JSNT 249; Clark, London-New York 2003). En este apartado sigo fundamentalmente los análisis de este autor. 
dominación al que sirven y del que no pueden escapar, lo que tampoco les exime de responsabilidad.

En el evangelio hay dos casos de cómo ejercen el poder estos que "parecen ser jefes de las naciones".

- Herodes, el día de su cumpleaños, da un banquete a su magnates, a los tribunos y los principales de Galilea $(6,21)$. El banquete es el lugar por antonomasia donde se expresa el honor del anfitrión. La danza de la hija de Herodías gustó mucho a tan distinguidos comensales y a Herodes, hasta el punto de que este le prometió darle lo que le pidiese "hasta la mitad de su reino". La muchacha, siguiendo la intriga de su madre, le pidió la cabeza de Juan Bautista. Herodes respetaba a Juan y le escuchaba con gusto $(6,20)$, pero no podía negarse a la petición "a causa del juramento y de los comensales" $(6,26)$. Está en juego su honor, ha dado su palabra en el contexto más solemne, está atrapado por un sistema de dominación. No se trata de exculpar a Herodes, pero sí de ver que es una pieza de una red de poder que controla aquella sociedad.

- El otro caso es el de Pilato, prefecto romano de Judea. Está convencido de la inocencia de Jesús y quiere liberarle. Pero las presiones de las autoridades judías, el griterío de una chusma, la dependencia del legado de Siria, le llevan a ceder y a mandar a Jesús a la cruz. Tampoco se trata de exculpar a Pilato, sino de hacer ver que está atrapado en un sistema de dominación; los jefes de las naciones parece que lo son, pero más en verdad, son piezas de una perversa y escondida dinámica de poder.

Marcos quiere que nos preguntemos ¿los que gobiernan son los que realmente detentan el poder?, ¿ los que son considerados poderosos son tan poderosos? ${ }^{12}$.

Continúa el texto: "Pero no ha de ser así entre vosotros" (v. 43). Una afirmación tajante, en presente: en la comunidad cristiana no caben estas actitudes, deben visibilizarse unos comportamientos radicalmente alternativos, que se describen a continuación.

"quienquiera ser grande (megas) entre vosotros será vuestro servidor (diakonos) y quienquiera entre vosotros ser el primero (prôtos) será esclavo (doulos) de todos" (vv 43-44).

2 Alberto de Mingo, But It Is Not..., 123. 
En 9, 35 decía: "si alguno quiere ser el primero, será el último y servidor (diakonos) de todos". En 10, 44 no dice servidor (diakonos), sino esclavo (doulos), que es mucho más fuerte. Los esclavos en aquel tiempo ejercían funciones muy diversas y algunas requerían cierta formación ( $\mathrm{p}$. ej. pedagogos o maestros), pero su condición era la ínfima en la escala social, porque carecían de libertad; eran propiedad de sus amos, tenían que estar a su plena disposición, servirlos y cumplir su voluntad. Jesús utiliza una metáfora de una radicalidad total. Supone una reversión de los valores convencionales en las relaciones humanas. La comunidad cristiana plantea una alternativa radical.

El versículo final es la culminación de estas palabras de Jesús y, en realidad, de toda la sección, porque presentan la justificación cristológica de la actitudes que Jesús exige: "Porque el Hijo del hombre no ha venido a ser servido sino a servir, y dar su vida en rescate por muchos" (v. 45).

He aquí una síntesis de toda la vida de Jesús y también de su finalidad. En los tres anuncios de la pasión se menciona al Hijo del hombre, que será entregado, que debe sufrir $(8,31 ; 9,31 ; 10,33)$. Aquí se dice que el Hijo del hombre sirve y entrega su vida. Es notable porque el Hijo del hombre en el libro de Daniel y en la literatura judía es una figura gloriosa, que recibe el poder de Dios, que juzga.

Jesús tiene toda la autoridad (exousia), dada por Dios, que el pueblo percibe y queda sorprendido, pero ha estado totalmente al servicio de los seres humanos. No es un poder impositivo o que fuerce la libertad. A veces se dice que Jesús tiene poder (dunamis) que sana, pero que no utiliza nunca para favorecer su persona o su misión. Le retan a ello, pero Jesús no tiene poder para bajar de la cruz (Mc 15, 29-32).

En v. 45b dice "el Hijo del hombre ha venido ... para dar su vida en rescate por muchos". Rescate, el griego lutron, era el precio que se pagaba para liberar a un esclavo. Aquí se está utilizando de forma metafórica. Hay con toda probabilidad una referencia al Siervo de Yahvé que expía (asam) por los pecados (Is 53,10). Sin embargo para la expiación se usan otras palabras griegas, no lutron, que solo se usa en este lugar. ¿Por qué aquí se usa lutron, el rescate de un esclavo? Notemos que en el contexto se dice que los líderes de la comunidad deben ser "esclavos de todos".

Una metáfora puede tener una gran riqueza de sentido. Entregar la vida como rescate -sin eliminar el aspecto expiatorio- puede entenderse 
como liberación de las ideologías y relaciones de poder, que entrampan al mundo, incluidos sus jefes ${ }^{13}$; es la liberación de lo que antes llamaba el sistema de dominación. La libertad de la que Jesús habla se encuentra en una sociedad nueva y alternativa, en la que nuevos valores y nuevas relaciones hacen libres a sus miembros. La llamada a ser "esclavos de todos" no es mera llamada a la humildad y a la amabilidad a los líderes de la comunidad, sino una llamada a practicar el liderazgo de una forma subversiva respecto a la red de poder que existe en el mundo ${ }^{14}$.

Los líderes de la Iglesia en nuestros días están desafiados a expresar no solo con palabras y documentos, sino también con su testimonio y sus prácticas caminos para subvertir el sistema que domina las naciones ${ }^{15}$.

Marcos es el evangelio más antiguo y vamos a ver a continuación brevemente como desarrollan los otros evangelios este tema de capital importancia.

\section{MATEO}

En Mt las cuestiones eclesiológicas tienen una especial importancia. Los ministerios se van estabilizando y el peligro es que las estructuras de poder al estilo mundano se introduzcan en el seno de la Iglesia. El capítulo 23 es una durísima polémica con los escribas y fariseos. En medio introduce una advertencia a los líderes de la comunidad cristiana, que deben tener un comportamiento radicalmente diferente (23, 8-12). Entre los seguidores de Jesús no se deben utilizar títulos honoríficos ni nada que rompa la radical fraternidad. "Uno solo es vuestro maestro y todos vosotros sois hermanos". Dios como único Padre impide que las relaciones patriarcales se introduzcan en el seno de la comunidad, lo que fue un peligro muy real que, además, acabó consumándose.

\section{LUCAS}

Es el único sinóptico que presenta un discurso de Jesús en la última cena $(22,14-38)$, en el que introduce unas palabras semejantes a las que acabamos de ver en Mc 10, 42-44.

13 Alberto de Mingo, But It Is Not..., 154

14 Alberto de Mingo, But It Is Not...., 208.

15 Alberto de Mingo, But It Is Not...., 213. 
Una consideración antropológica previa nos puede ser ahora muy útil. En toda comida, hasta en la cotidiana y familiar, pero mucho más en un banquete solemne, se guarda un cierto ritual ${ }^{16}$. Se dice que "si quieres conocer un grupo observa como come": observa la disposición en la mesa, los lugares que cada uno ocupa, el protocolo que siempre existe, cuándo, cómo y qué comen. Suele presidir el "paterfamilias", hay lugares más o menos honoríficos, hay quienes comen y quienes sirven. El banquete refleja un orden social.

Es importante que Lc sitúe las palabras de Jesús en un banquete y, además, aluda en ellas a lo que sucede en un banquete. No vamos a entrar ahora en las relaciones literarias entre la versión marcana de las palabras y la lucana (Lc 22, 24-27). Cito solo el versículo final:

“QQuién es mayor, el que está a la mesa o el que sirve?

¿No es el que está a la mesa?

Pues yo estoy en medio de vosotros como el que sirve".

Parece que Jesús está sirviendo a la mesa. Lo propio de los líderes de la comunidad cristiana no es el honor, ni el primer puesto, sino el servir a ejemplo de Jesús.

Pero Jesús esta expresando la sorprendente forma de actuar de Dios. En la breve y bellísima parábola de Lc 12, 35-37 se habla de los esclavos que esperan vigilantes en la noche la venida de su señor. Cuando este llega se esperaría que los esclavos le lavasen los pies, le atendiesen y le diesen de comer. Pero sucede exactamente al revés: "Dichosos los siervos a quienes el señor, al venir, encuentre despiertos: yo os aseguro que se ceñirá, les hará ponerse a la mesa y, yendo de uno a otro, les servirá" (12, 3 7). Dios es un señor que sirve.

Los banquetes son el lugar por antonomasia donde se refleja el orden social y las relaciones de poder. Pues bien, en los evangelios, sobre todo en Lc, Jesús en los banquetes adopta comportamientos contraculturales, que levantan críticas y murmuraciones $(5,29-32 ; 15,1-2 ; 19,1-10$; $7,37-50 ; 11,37-52)$ porque es el mejor lugar para expresar su forma alternativa de entender las relaciones sociales. Y esto nace de su peculiar experiencia de Dios.

16 Estas consideraciones antropológicas, aplicadas al análisis del NT, las he desarrollado en mi obra La mesa compartida. Estudios del NT desde las ciencias sociales (Sal Terrae, Santander 1994). 
Dios no es el todopoderoso, sino el misericordioso.

La mediación histórica de Dios no es el poder, sino el servicio.

Esto es lo que tiene que visibilizar la comunidad cristiana con su vida interna y convertirlo en propuesta para transformar la sociedad.

\section{JUAN}

Después de lo dicho se entiende fácilmente el gesto que Jesús realiza en el evangelio de Juan durante la última cena. El evangelista introduce el episodio con solemnidad impresionante: "Antes de la fiesta de Pascua, sabiendo Jesús que había llegado su hora de pasar de este mundo al Padre, habiendo amado a los suyos que estaban en el mundo, los amó hasta el extremo" $(13,1)$. Es decisivo el contexto de un banquete, de una cena solemne. En los Sinópticos Jesús confiere a unos elementos de la cena-el pan y la copa de vino- una dimensión nueva para expresar el sentido de su vida (Mc 14, 22-25 y par.). Juan no cuenta esto. Pero en su evangelio, Jesús también utiliza un rito de la cena, el previo, el lavatorio de los pies, para expresar el sentido de toda su vida. Lava los pies a los discípulos, la tarea de los esclavos. Pedro no entiende y se resiste. Jesús es el Señor y el Maestro, pero quiere dejarles este ejemplo "para que también vosotros os lavéis los pies unos a otros" (Jn 13, 14-15). El servicio del esclavo es el paradigma del liderazgo en la comunidad cristiana.

\section{RePENSAR Un Dios SIN PODER}

He subrayado que Jesús posee una insólita autoridad, pero que rechaza absolutamente el poder coercitivo -la imposición de su voluntad a otros- para llevar adelante el plan de Dios, que es su misión. Su autoridad sorprende y su renuncia al uso del poder decepciona, pero ambas actitudes son inseparables y hunden sus raíces en la profunda y peculiar experiencia de Dios que tiene Jesús. De modo que la reflexión sobre Jesús y el poder nos lleva necesariamente a preguntarnos ¿cómo es el Dios de Jesús?, ¿qué relación guarda con el poder?

Nos adentramos en un punto especialmente delicado, en el que el exégeta se siente muy cercano al teólogo, muy dispuesto a dejarle, con modestia, la palabra.

En las tradiciones religiosas -desde luego en el culto imperial romano- se identificaba a Dios con el poder: La helenización que muy pronto 
experimentó el cristianismo hizo que el Dios de una determinada filosofía fuese sustituyendo al Dios de Jesús. Así la "primacía del poder" se sobrepuso a la "primacía del amor". El Pantokrator de la cultura helenística pronto suplantó al Dios que se reveló en Jesús, que nació y vivió en debilidad y pobreza, y murió ejecutado entre malhechores. A lo largo de los siglos, la institución eclesiástica, más preocupada por su poder que por su autoridad moral, al hablar del misterio de Dios ha insistido más en su poder infinito (a partir de consideraciones filosóficas) que en su misericordia sin límites (como se expresa en la vida de Jesús).

Se impone, por tanto, replantear las relaciones de Dios con el poder. Propongo tres puntos, que requerirían un desarrollo mucho más amplio.

\section{MarCos 15, 39}

El evangelio de Mc es la revelación de Jesús como Mesías e Hijo de Dios a través de la cruz. Esto es lo que no entienden los discípulos que piensan siempre lo divino en términos de poder y de honor. Participan de "los pensamientos de los hombres". El centurión viendo como había expirado dijo: "Verdaderamente este era Hijo de Dios" (15, 39). Esta es la auténtica confesión porque se realiza a los pies de la cruz. Mc está diciendo que el Hijo de Dios no es el emperador, que se atribuía este título. En la cruz - consecuencia de su vida- se revela Jesús como Hijo de Dios. Y es también revelación del Dios a quien Jesús llama Padre. No es un poder intramundano; no interviene para salvar a su hijo. El Gólgota estuvo cubierto de tinieblas. La cábala judía dice que Dios lo llena todo, y que tuvo que limitarse y retirarse para dejar sitio a la creación. Pero añade la Cábala que al retirarse, de alguna forma, Dios no deja de irradiar. Dios acompaña al crucificado, más aún, sufre con él, en medio del silencio de su ausencia.

En la historia no hay que buscar a Dios en el poder, en la magnificencia, en lo extraordinario deslumbrante, sino en los crucificados, en los hambrientos y sedientos, en los enfermos y desnudos, en los encarcelados y forasteros.

\section{Corintios $1,18-25$}

El tema de la cruz en Pablo tiene una profundidad enorme, y su valor más que cristológico es teológico. En la cruz se desvela una nueva y des- 
concertante imagen de Dios. Voy a aludir solo al texto inicial de 1 Cor (por razones de espacio no voy a hablar de Fil 2, 6-11).

El apóstol quiere corregir una serie de problemas que se han planteado en su comunidad (camarillas enfrentadas, confusión en temas sexuales, pugnas por los carismas considerados más valiosos, divisiones en la misma celebración de la cena del Señor, desórdenes en las asambleas, etc.) y cuya raíz está en los criterios humanos sobre el poder, el honor y la sabiduría. Pablo, con una retórica brillante y apasionada, va a esta raíz: el Dios que se ha revelado en la cruz de Cristo nos enseña a ver y valorar la realidad de una forma radicalmente alternativa a la socialmente dominante.

"La predicación de la cruz es una locura" $(1,18)$. En efecto, la cruz es un patíbulo infamante, vergonzoso, que solo se aplicaba a esclavos y a lo más ínfimo de la sociedad. "Nosotros predicamos a un Cristo crucificado, escándalo para los judíos y locura para los gentiles" (1, 23). "No quise saber entre vosotros sino a Jesucristo, y este crucificado" $(2,2)$. Pero, a la vez, este Cristo crucificado es "sabiduría y fuerza de Dios"17, que nos debe liberar de los criterios del mundo y propiciar unos comportamientos radicalmente alternativos. Stanislas Breton nos acerca a la radical función crítica de la cruz precisamente por su revelación del ser de Dios:

"La religión cristiana en su originalidad crística se reclama de un Dios débil, más allá del ser y de la esencia, una especie de nada activa que sobrepasa, desafiándolos todos los poderes de fascinación para ponerlos en cuestión"18.

En una línea semejante afirma Daniel Marguerat:

“¿Por qué el Dios de la cruz es inaceptable? Simplemente porque la sabiduría filosófica griega situaba a Dios en las antípodas: lo asociaba al poder, al saber, a la perfección. Es el Dios de nuestro imaginario que lo sabe todo, que lo puede todo, lo ve todo, lo dice todo... Creer que Dios desvela el íntimo secreto de su ser en el silencio de esta muerte es seguramente un desafío a la razón y un desafío a nuestro imaginario"19.

17 Para lo que sigue M. Mallofret, "El mensaje de la cruz: síntesis teológica de 1 Cor 1-4 y Flp 2, 5-11", Isidorianum XV (2006) 137-191.

18 Saint Paul (Presses Universitaires de France, Paris 1988).

19 Paul de Tarse. Un homme aux prises avec Dieu (Édition du Moulin, Poliez-le-Grand 2011) 64. 
La Palabra de Dios es siempre interpelante, denuncia la inhumanidad y nos cuestiona desde el prójimo. Ya al principio de la Biblia la gran pregunta que Dios dirige al hombre es “¿Dónde está tu hermano?” La Palabra de la Cruz saca a la luz a todas las víctimas de la historia, a todos los sufrimientos ocultos sobre los que se edifica nuestro presente y plantea la gran exigencia de que el futuro no sea simplemente la prolongación de lo existente, sino que -haciendo memoria de la Cruz, que nos habla de todas las cruces- descubramos los derechos conculcados y las posibilidades sofocadas, para que el futuro sea realmente nuevo.

Cito las palabras de un autor español:

"El Crucificado (el logos tou staurou) significa la fuerza y la sabiduría de Dios que, en las antípodas de todos los poderes de este mundo, permanece para siempre como el gran interrogante que cuestiona nuestras vidas desde la debilidad del amor" ${ }^{\prime 2}$.

\section{LA RESURRECCIÓN}

En la Resurrección de Jesús se manifiesta el poder de Dios, pero es un poder que no compita con los poderes de este mundo. Está más allá.

La resurrección es la afirmación de que la última palabra no es de la de los que "parecen ser jefes", Caifás y Pilato, sino de Jesús, la víctima inocente; que la última palabra no corresponde ni al Dios del Templo ni al Dios del Imperio, sino al Dios del Crucificado.

Pero hay más. La Resurrección es la novedad radical - "lo imposible necesario" ${ }^{21}$ se la ha denominado- porque abre un horizonte insospechado que sitúa toda la realidad en una perspectiva nueva. La gran tarea de los creyentes es precisamente introducir la historia en la perspectiva abierta por la resurrección. Es posible una sociedad alternativa realmente a la establecida, existen más posibilidades de las que puede contabilizar un mero cálculo racional realizado sobre los datos tangibles del presente. Esto hay que hacerlo sin precipitaciones, sin olvidarnos de las limitaciones de lo humano, también de la convivencia, en la que inevitablemente se da el poder, que tiene que ser aceptado en su provisionalidad, regulándolo y controlándolo, para que sea, en lo posible, más libre y menos forzado, sobre todo más fraterno y menos jerárquico.

\footnotetext{
20 Manuel Mallofret, "El mensaje de la cruz...," 155.

21 Cfr. El libro de Javier Gomá, Necesario pero imposible (Taurus, Madrid 2013).
} 


\section{REFLEXIONES FINALES}

Voy a concluir resumiendo algunos de los puntos exegéticos y sacando algunas conclusiones de carácter eclesial y social. Estos puntos los planteo de forma esquemática y con el deseo de abrir vías de reflexión y actuación.

1. El Reinado de Dios escatológico, futuro, que Jesús anuncia será el Reino del Padre y supondrá la plena fraternidad, la superación de las relaciones de poder y dominación. Jesús anuncia que este Reino del Padre se está ya abriendo camino en la historia, de forma incoada y entre mil dificultades, pero es una posibilidad que se ofrece a los humanos, y que es radicalmente crítica con el poder del Imperio, que diviniza al emperador, y con el poder de la aristocracia sacerdotal que detenta el poder del Templo.

2. Jesús no pretendió fundar una institución religiosa, sino que se dirigió a Israel y buscaba su renovación radical. Proclamaba un gran año jubilar, en el que Dios ofrecía el perdón, en el que todas las deudas quedaban perdonadas, en el que las exclusiones sociales debían superarse.

3. Jesús tenía una insólita autoridad moral, pero no ejercía ningún poder coercitivo. Rechaza el poder que le proponen como una tentación. Jesús habla y actúa a partir de una profunda e íntima experiencia de Dios. Los valores escatológicos y definitivos que propone son incompatibles con el uso del poder, que es siempre expresión de lo provisional y relativo.

4. Los evangelios recogen fielmente el proyecto de Jesús, pero reinterpretan toda su vida a la luz de su muerte y de la experiencia pascual. Son escritos de la segunda generación de discípulos, posteriores al año 70. Las comunidades de las que proceden pueden no haber roto con el judaísmo, pero sus escritos no se dirigen a todo Israel, sino a comunidades concretas. Su objetivo no es ya configurar las relaciones sociales de un pueblo, sino la vida interna de unas comunidades determinadas. Pretenden que esas comunidades de seguidores de Jesús sean radicalmente fraternas, que en ellas no haya relaciones de poder o piramidales; al contrario, en ellas los pobres, las gentes menos consideradas socialmente, deben gozar de una consideración especial. La ayuda a los necesitados y la hospitalidad, entendida como la acogida de los desvalidos y forasteros, fue probablemente lo que hizo más atractivas a las comunidades cristianas de los orígenes y fue un factor decisivo de su crecimiento. 
La propuesta de Jesús -viendo el mundo a la luz de Dios- resultaba profundamente contracultural e implicaba un cambio radical de los valores. La asunción positiva de la situación de pobreza, de marginación, de deshonor podía convertirse en ocasión para generar alternativas de superior calidad moral. Es lo que se llama el proceso de "autoestigmatización". Esto que vale para todos los discípulos de Jesús, se les pide de forma especial a los líderes de la comunidad: que asuman el rol del esclavo de todos, de servidores, que se sitúen los últimos, que se identifiquen con los menos considerados (los niños). Es una forma radicalmente alternativa de ejercer el poder, que en todo grupo humano se da. En los discípulos que no entienden se refleja la Iglesia de todos los tiempos. Pero Jesús no ceja en su enseñanza. Lo que está en juego es aceptar el papel social y el sentido teológico de la cruz: en la cruz se revela un Dios que altera nuestro imaginario religioso y subvierte los valores hegemónicos.

5. De lo dicho se deduce que la Iglesia debe ser una comunidad en la que el poder -que seguirá existiendo- tendrá que ejercerse de forma especialmente controlada, transparente, fraterna, servicial y participativa; deberá ejercerse desde los últimos y teniendo en cuenta prioritariamente sus intereses; no caben ni títulos ni distinciones honoríficas. La forma de elegir a los responsables de los ministerios debe ser democrática y participativa. En el NT se reitera la participación de la comunidad en las grandes decisiones: en la elección del sucesor de Judas (Hch 1, 21-26), en la elección de los líderes de los helenistas (Hch 6, 3), en el "Concilio de Jerusalén” (Hch 15, 22) etc. En el NT a los responsables se les exige transparencia en su gestión (Pedro en Hch 11, 19 ss tiene que responder ante la comunidad de Jerusalén de su actitud en Cesaréa al bautizar a Cornelio y a su casa y al compartir la mesa con ellos; Pablo tiene un cuidado exquisito de que la colecta a favor de la Iglesia de Jerusalén se gestione de forma transparente). En todo esto se juega el que la Iglesia sea en la historia sacramento del Reino de $\operatorname{Dios}^{22}$.

Desgraciadamente vemos que la Iglesia está muy lejos de responder a estos principios. El Cardenal Martini decía que llevaba más de doscientos

22 Carlos Schickendantz, "La Iglesia "se enriquece con la evolución de la vida social humana» (GS 44, 3). Estructuras históricas e institución divina en el contexto de la modernidad", en Fredy Parra y Agustina Serrano (eds.), La inteligencia de la esperanza. Homenaje al profesor Juan Noemi Callejas (Suplemento a Teología y Vida. Pontificia Universidad Católica de Chile, Santiago 2012) 313-338: habla del cambio organizativo del poder en la Iglesia como exigencia de la evangelización. 
años de retraso respecto a las sociedades contemporáneas. La organización del poder en la Iglesia, absolutista, piramidal y jerárquica (con expresiones absolutamente anacrónicas), la cooptación secreta y arbitraria de sus dirigentes, los mecanismos de control ideológico, son inaceptables para la mentalidad actual y se contraponen frontalmente con el proyecto de Jesús y con el testimonio de las comunidades cristianas de los orígenes.

Después de siglos de soportar esta situación parece que ahora, con el Papa Francisco, un espíritu profundamente renovador quiere cambiar esta situación inaceptable e insostenible en la Iglesia.

6. Pero la Iglesia no es un fin en sí misma. Debe servir al mundo, ante todo presentando el Evangelio y mostrando su carácter humanizado y liberador. La Iglesia, como gran institución, tiene mucho que cambiar y tendría mucho que ofrecer.

Pero ahora pienso en tantas Iglesias locales y comunidades concretas que pueden ser -con frecuencia son- ejemplos de vida fraterna, lugares de acogida y ayuda, embrión de un mundo nuevo. Esto es lo que podemos y debemos impulsar. Estas comunidades, insisto, no son fin en sí misas ¿Cómo sirven al mundo?

Algunos han hablado de "comunidades de contraste" (Kontrastierungsgeminde), porque se plantan ante el mundo sin mezclarse con él y presentándole los valores alternativos del Reino de Dios ${ }^{23}$. Yo preferiría hablar de comunidades pioneras de nueva humanidad, que son minorías creativas que, en efecto, visibilizan los valores alternativos del Reino de Dios, en los que la hermandad sustituye a las relaciones patriarcales y de poder, pero que hacen más: tienen la visión y valentía anti-idolátrica de los profetas para sacar a la luz y denunciar los poderes decisivos, que suelen ocultarse, del sistema de dominación, son como la levadura que se mete en la masa para abrir caminos nuevos en la sociedad, hacen propuestas nuevas y humanizadoras a partir de los intereses de los más necesitados. Son comunidades que no aspiran al poder político, porque su influencia se ejerce en lo prepolítico y cultural, que es donde de incuban los cambios sociales profundos.

23 Esta postura está muy bien representada por GERHARD LOHFINK, que dejó su cátedra de Nuevo Testamento en Tubinga para dedicarse plenamente a la "Katholische Integrierte Gemeinde". Pueden verse sus dos obras: La Iglesia que Jesús quería (DDB, Bilbao 1986) y Jesús de Nazaret. Qué quiso, quién fue (Herder, Barcelona 2013). 
Resumen: Se comienza estableciendo un marco teórico sobre el carácter histórico del poder y sus relaciones con el concepto de autoridad. Después se sitúa el marco del ministerio de Jesús y los poderes judíos e imperiales que le condicionaron. Se presenta la autoridad moral indudable de Jesús basada en su peculiar experiencia religiosa. Posteriormente se analiza el evangelio de Marcos para descubrir la tensión enorme entre el proyecto de Jesús y el afán de poder de los discípulos. El examen de la Escritura nos enfrenta con un Dios no-poder, que se revela en la cruz de Jesús. Se concluye con unas reflexiones sobre la autoridad de Jesús, que carece de todo poder coercitivo precisamente porque es el testimonio del Reino de Dios escatológico y sobre como tiene que afrontar la Iglesia la organización del poder y su relación con los poderes históricos.

Palabras clave: Poder, autoridad, Jesús, discípulos, Iglesia, Dios.

Abstract: The first approach is a theoretical frame: the relationship between historical power and the notion of authority. Then the consideration of Jesus' ministry in its jewish and imperial context. Jesus' undeniable moral authority is based on his unique religious experience. Marc's gospel shows the tension between Jesus' project and the disciples seeking power. Scripture presents a non-power God, who reveals himself in Jesus' cross. Jesus' authority is totally free of forceful power, it is the witnessing of the eschatological kingdom of God. The paper concludes with reflections on how should the Church manage power and deal with historical powers.

Keywords: Power, authority, Jesus, disciples, Church, God. 